\title{
Analytical and Numerical Investigation of Free Vibration Behavior for Sandwich Plate with Functionally Graded Porous Metal Core
}

\author{
Emad Kadum Njim ${ }^{1}$, Sadeq H. Bakhy ${ }^{1}$ and Muhannad Al-Waily ${ }^{2 *}$ \\ ${ }^{1}$ University of Technology, Mechanical Engineering Department, Baghdad, Iraq \\ ${ }^{2}$ University of Kufa, Faculty of Engineering, Mechanical Engineering Department, Najaf, Iraq
}

\begin{abstract}
The current work presents a free vibration analysis of a simply supported rectangular functionally graded sandwich plate using a new analytical model. The core of the sandwich plate is made up of porous metal, and the top and bottom faces are made up of homogenous materials. The core metal properties are assumed to be porosity dependent and graded in the thickness direction according to a simple power-law distribution in terms of the volume fractions of the constituents. The contribution of this paper is to evaluate the performance of functionally graded porous materials (FGPMs) as it is used for many biomedical applications, particularly in tissue engineering. Theoretical formulations are based on the classical plate theory to find the free vibration characteristics of the imperfect FGM sandwich plate and include different parameters. Parameters included are

ARTICLE INFO

Article history:

Received: 19 February 2021

Accepted: 30 April 2021

Published: 31 July 2021

DOI: https://doi.org/10.47836/pjst.29.3.39

E-mail addresses:

emad.njim@gmail.com (Emad Kadum Njim)

20093@uotechnology.edu.iq (Sadeq H. Bakhy)

muhanedl.alwaeli@uokufa.edu.iq (Muhannad Al-Waily)

*Corresponding author

graded distributions of porosity, power-law index, core metal type, and aspect ratios. A numerical investigation using finite element analysis (FEA) and the modal analysis was conducted with the assistance of the commercial ANSYS-2020-R2 software to validate the analytical solution. To detect the various parameters influencing the fundamental frequencies of sandwich plate comprehensive numerical results are presented in dimensionless tabular and graphical forms. The results reveal that the
\end{abstract}


frequency parameter of the sandwich plate increases with the increase of the porosity parameter and number of the constraints in the boundary conditions. Furthermore, the increase in the number of layers leads to an increase in the accuracy of the results for the same FGM core thickness. An accepted agreement can be observed between the proposed analytical solution and numerical results with a maximum error discrepancy of $8 \%$.

Keywords: Free vibration, frequency, functionally graded, porous, sandwich plate

\section{INTRODUCTION}

Functionally graded materials (FGMs) are composites with a continuous variation of material properties from one surface to another, thus eliminating the stress concentration found in laminated composites (Thai et al., 2013). Due to its excellent stiffness and toughness and high strength-to-weight ratio, the sandwich structure can be used in many applications, such as automobiles, ship development, transportation, and airlines. This feature has attracted many considerations, and many researchers have conducted continuous static and dynamic inspections of structural engineering under various environmental conditions. Consequently, due to the excellent performance, the use of sandwich structures in the field of micro auxiliary frames is continuously developing (Hadji et al., 2011). Therefore, in a wide range of FGM material types and benefits, it is vital to explore the static and dynamic behavior of auxiliary personnel with FGM, such as beams and plates (Kiani et al., 2011; Anderson, 2003). Due to technical problems in the manufacturing process, pores and micropores may be formed inside the FGM plate, which may cause material quality degradation. The assembly strategy of FGM's is a creative area. The sintering strategy is most widely used because of its cost-saving advantage ratio. In any case, the sintering cycle empowers the development of microvoids or porosities (Kumar et al., 2021). Although crucial improvements have been observed here recently, porosity is still an ongoing defect in FGM. As mentioned above, porosity results from the assembly cycle and can reduce the material's quality. Therefore, this defect's effect is to consider the influence of pores on the unique properties of the transfer pores of the FGM structure (Muc \& Flis, 2021). Wang and $\mathrm{Zu}$ (2017) considered a rectangular plate's vibration behavior mainly evaluated, pores, and moves in a warm area. The vibration analysis of a porous functionally graded plate made of a mixture of Aluminum ( $\mathrm{Al})$ and alumina $\left(\mathrm{Al}_{2} \mathrm{O}_{3}\right)$ installed in an elastic medium was introduced by Hayat and Meriem (2019). Zhang et al. (2019) changed the topological design, porosity, and mechanical behavior of functionally graded porous metal biomaterials with added design. Singh and Harsha (2020) studied the effect of porosity and temperature on sandwich S-FGM plates.

Dang et al. (2018) also discussed the free vibration characteristics, which can be inferred from the pores in the FGM test of the rotating graphene-enhanced permeable 
nanocomposite barrel shell. Regarding the porosity distribution, Nguyen et al. (2018) studied the mechanical conduction of porous FGP. Therefore, they considered two different porosities, both of which move in the thickness direction (specifically, evenly distributed and unevenly distributed). Zhang and Wang (2017) created eight other porous material structures with varying pore distributions, including gradient distributions. They exposed them to some mechanical tests to evaluate essential material properties, such as Young's modulus. Functionally graded porous materials combine the qualities of FGM and porous materials. In addition to the extremely high stiffness-to-weight ratio, they also have excellent mechanical properties to clarify why these materials are widely used in various fields (Kiani \& Eslami, 2012). Usually, the variation of porosity through the thickness of porous plates causes a smooth change in mechanical properties. Therefore, this type of material has received wide applications in aerospace, marine, and biomedical application (Rezaei \& Said 2015). Although there are exceptional circumstances, the material's strength will decrease due to these holes' presence, which should be kept in mind for mechanical behavior (Merdaci, 2019).

Kim et al. (2019) proposed three porosity distributions in the thickness direction, together with the research developed by Coskun et al. (2019) and Zhao et al. (2019). The inspiration for the closure came from the uniform distribution of Merdaci (2019). His research recognized that typical functionally graded ceramic/metal square plates have different porosity distributions throughout the thickness. Numerous studies on free vibration for isotropic and functionally graded plates have been reported. Chakraverty and Pradhan (2014) studied the free vibration of thin FG rectangular plates in complex environments. Wattanasakulponga and Ungbhakorn (2014) used a combination of linear and nonlinear analysis to study the influence of porosity parameters on the frequency parameters of FGM constrained end beams. Although some studies have been conducted on sandwich structures with FGM cores to evaluate their bending behavior (Tossapanon \& Wattanasakulpong, 2017; Meiche et al., 2011; Neves et al., 2013) and flexural strength (Kapuria et al., 2008; Lashkari \& Rahmani, 2016), sandwich structures' free vibration and stability issues fabricated by functionally gradient have been studied. However, investigations on the free vibration of FGM structures with porous metal topology are still limited. The objective of the present research is to investigate the free vibration analysis of an imperfect simplysupported sandwich plate. In this paper, we assume that the functionally graded part is made from one constituent material, whose material properties are changed due to various porosity distribution and graded in the thickness direction according to a power-law distribution. A new representation of the classical plate theory (CPT) is developed to find the free vibration features according to various FGM parameters. The proposed mathematical model used for approximating FGM core properties, such as Young's modulus (E) and material density ( $\rho$ ) equations, is verified by comparisons between material property results obtained from 
volume fraction analysis and the proposed models. The paper also explores the influence of some parameters on the free vibration of the functionally graded sandwich plates such as power-law index, porous metal type, porosity ratio, and length to thickness ratios. By using the FEA method represented by ANSYS software, results of natural frequency and mode shapes of the imperfect FGM sandwich plate with different boundary conditions are presented. Furthermore, the core part is divided into (2-16) layers, and the frequency analysis is performed for both square and rectangular plates to identify the effect of the increasing number of layers on FG structure performance. The numerical results presented herein for functionally graded porous materials are not available in the literature, and hence, should be of interest to the industrial applications.

\section{MATERIALS AND METHOD}

Consider a thin rectangular FGM plate composed of ceramic and metal, in which the upper surface is metal-rich, and the underlying surface is ceramic-rich, respectively. The FGM plate is supposed to carry porosities that disperse evenly or unevenly along the platethickness direction (Figure 1). The plate's length, width, and thickness are denoted by $a, b$ and $h$, respectively. A Cartesian coordinate system $(O, x, y, z)$ on the plate's middle surface is adopted to describe the plate motion, where $x$ and $y$ define the in-plane coordinates and $z$ denotes the out-of-plane coordinate of the plate. The origin $O$ is at one of the plate corners; however, the volume fraction of FG plate layers can be represented either in exponential law, sigmoid law, or power-law. The ceramic volume fraction $V c$ is assumed to follow a simple power distribution as Equation 1 (Natarajan \& Manickam, 2012).

$$
\mathrm{V}_{\mathrm{c}}(\mathrm{z})=\left(\frac{\mathrm{z}+\frac{\mathrm{h}}{2}}{\mathrm{~h}}\right)^{\mathrm{k}}
$$

The volume fraction sum of metal and ceramic is stated as: $V_{m}(z)+V_{c}(z)=1$, where $V_{m}$ and $V_{c}$ are volume fractions of metal and ceramic, respectively $k$ is power-law variation index and is a non-negative variable parameter, in which $k \in[0, \infty)$. The value of $k$ equal to zero represents a fully ceramic plate, whereas infinite $k$ indicates a fully metallic plate.

Assuming porosities disperse equally in the metal and ceramic phases, the general material property of the imperfect FGM plate, with a porosity volume fraction $\beta(\beta<<1)$, takes the modified form as Equation 2.

$$
\mathrm{P}(\mathrm{z})=\left(\mathrm{P}_{\mathrm{c}}-\mathrm{P}_{\mathrm{m}}\right)\left(\frac{\mathrm{z}+\frac{\mathrm{h}}{2}}{\mathrm{~h}}\right)^{\mathrm{k}}+\mathrm{P}_{\mathrm{m}}-\frac{\beta}{2}\left(\mathrm{P}_{\mathrm{c}}+\mathrm{P}_{\mathrm{m}}\right)
$$


In Equation 2, $P_{c}$ and $P_{m}$; are the values of material properties of ceramic and metal, constituents of the FG plate, respectively. For our present formulations, the material properties, viz. Young's modulus (E) and mass density ( $\rho$ ) are taken to vary along thickness direction except for Poisson's ratio (v), which will assume to be constant for simplicity, based on previous studies, reported by Delale and Erdogan (Meziane et al., 2014).

In general, the two-dimensional plate theories can be categorized into two types: (1) classical plate theory, in which the transverse shear deformation consequences are neglected, and (2) shear deformation plate theories. In the two-dimensional theory, the free vibration, thermal, and stability problems of the FGM structures, the displacement is represented in thickness. In contrast, the lateral displacement is independent of the lateral (or thickness) coordinates. The results of the mathematical model in the coupled governing equation are independent of lateral displacement. Therefore, this type of equation's analytical solution may be simpler than the three-dimensional elasticity theory (Ambartsumyan et al., 1970).

By using the classical plate theory (CPT), the displacement fields of FG plates across the plate thickness at a distance $z$ away from the middle surface are defined as Equation 3 (Chi \& Chung, 2006; Latifi et al., 2013).

$$
\begin{aligned}
& \mathrm{u}_{\mathrm{x}}(x, y, z)=-z \frac{\partial \mathrm{w}}{\partial \mathrm{x}} \\
& \mathrm{u}_{\mathrm{y}}(x, y, z)=-z \frac{\partial \mathrm{w}}{\partial \mathrm{y}} \\
& \mathrm{u}_{\mathrm{z}}(x, y, z)=w(x, y)
\end{aligned}
$$

Where $\mathrm{u}_{\mathrm{x}}, \mathrm{u}_{\mathrm{y},}$ and $\mathrm{u}_{\mathrm{z}}$ are the displacement of a point on the reference plane in the $\mathrm{x}, \mathrm{y}$, and $\mathrm{z}$ directions, respectively, and $\mathrm{w}$ represents the mid-plane lateral deflection (x-y plane). The Kirchoff model is not considered the effect of shear deformation due to bending and plane elongation. The non-zero linear strains associated with the displacement field can be expressed as Equation 4.

$$
\left\{\begin{array}{l}
\epsilon_{x x} \\
\epsilon_{y \gamma} \\
\gamma_{x y}
\end{array}\right\}=\left\{\begin{array}{l}
\frac{\partial u_{x}}{\partial x} \\
\frac{\partial u_{y}}{\partial y} \\
\frac{\partial u_{x}}{\partial y}+\frac{\partial u_{\gamma}}{\partial x}
\end{array}\right\}=\left\{\begin{array}{c}
-z \frac{\partial^{2} w}{\partial x^{2}} \\
-z \frac{\partial^{2} w}{\partial y^{2}} \\
-2 z \frac{\partial^{2} w}{\partial x \partial y}
\end{array}\right\}
$$

Where, $\epsilon_{x x}$ and $\epsilon_{y \gamma}$; are the components of the strain in $x$ and $y$ directions, respectively, and $\gamma_{x y}$; is the shear strain. Based on CPT, the stress-strain relations are given by Equation 5 (Wadee, 2001). 


$$
\begin{aligned}
\sigma_{\mathrm{xx}} & =\frac{\mathrm{E}}{1-v^{2}}\left(\varepsilon_{\mathrm{xx}}+v \varepsilon_{\mathrm{yy}}\right) \\
\sigma_{\mathrm{yy}} & =\frac{\mathrm{E}}{1-v^{2}}\left(\varepsilon_{\mathrm{yy}}+v \varepsilon_{\mathrm{xx}}\right) \\
\sigma_{\mathrm{xy}} & =\mathrm{G} \gamma_{\mathrm{xy}}=\frac{\mathrm{E}}{2(1+v)} \gamma_{\mathrm{xy}}
\end{aligned}
$$

The linear constitutive relations of a plate, such as the bending and twisting moments $M_{x x}, M_{y y}$, and $M_{x y}$ respectively on a plate element in the pure bending case can be written as Equation 6 (Baferani et al., 2011).

$$
\begin{aligned}
& \mathrm{M}_{\mathrm{xx}} \quad=\int_{-\frac{\mathrm{h}}{2}}^{\frac{\mathrm{h}}{2}} \sigma_{\mathrm{xx}} \mathrm{zdz}=-\mathrm{D}\left(\frac{\partial^{2} \mathrm{w}}{\partial \mathrm{x}^{2}}+v \frac{\partial^{2} \mathrm{w}}{\partial \mathrm{y}^{2}}\right) \\
& \mathrm{M}_{\mathrm{yy}} \quad=\int_{-\frac{\mathrm{h}}{2}}^{\frac{h}{2}} \sigma_{\mathrm{yy}} \mathrm{zdz}=-\mathrm{D}\left(v \frac{\partial^{2} \mathrm{w}}{\partial \mathrm{x}^{2}}+\frac{\partial^{2} \mathrm{w}}{\partial \mathrm{y}^{2}}\right) \\
& \mathrm{M}_{\mathrm{xy}} \quad=\int_{-\frac{\mathrm{h}}{2}}^{\frac{\mathrm{h}}{2}} \sigma_{\mathrm{xy}} \mathrm{zdz}=-(1-v) \mathrm{D} \frac{\partial^{2} \mathrm{w}}{\partial \mathrm{x} \partial \mathrm{y}}
\end{aligned}
$$

Where (Equation 7),

$$
\mathrm{D}=\frac{\mathrm{Eh}^{3}}{12\left(1-v^{2}\right)}
$$

the flexural rigidity of the plate. Alternatively, the second-order equilibrium equation of the Kirchhoff plate theory may be written as Equation 8.

$$
\frac{\partial^{2} M_{x x}}{\partial x^{2}}-2 \frac{\partial^{2} M_{x y}}{\partial x . \partial y}+\frac{\partial^{2} M_{y y}}{\partial y^{2}}=I_{0} \frac{\partial^{2} w}{\partial t^{2}}
$$

Substituting the expressions of bending and twisting moments in Equation 6, we can obtain the equation of equilibrium in terms of deflections $(w)$ of the plate as Equation 9.

$$
\mathrm{D}\left(\frac{\partial^{4} \mathrm{w}}{\partial \mathrm{x}^{4}}+2 \frac{\partial^{4} \mathrm{w}}{\partial \mathrm{x}^{2} \cdot \partial \mathrm{y}^{2}}+\frac{\partial^{4} \mathrm{w}}{\partial \mathrm{y}^{4}}\right)+\mathrm{I}_{0} \frac{\partial^{2} \mathrm{w}}{\partial \mathrm{t}^{2}}=0
$$

Where $\left(\mathrm{I}_{\mathrm{o}}\right)$ is the inertial coefficient of the plate. 


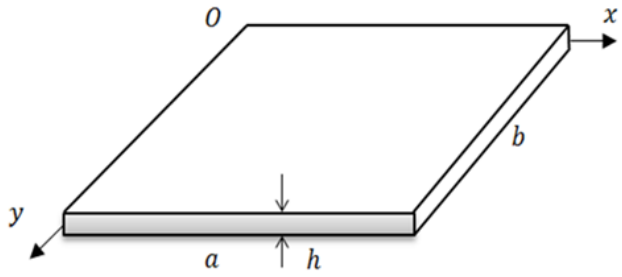

(a) Cartesian coordinate system

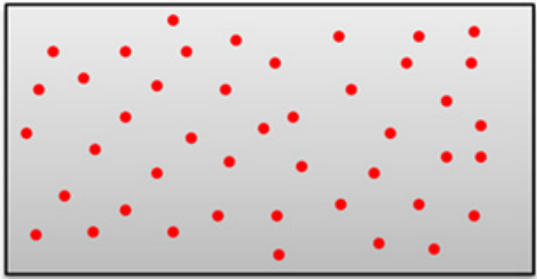

(b) Porosity with even distribution

Figure 1. A rectangular FGM plate

\section{Modeling Analysis for FGM Porous Core}

This section describes a new mathematical model used to evaluate the free vibration of the rectangular FG plate. By considering the imperfect FGM plate made mainly from one porous metal with a porosity volume fraction, $(\beta<<1)$ distributed equally in the core metal phase and graded through the plate thickness direction according to a power-law distribution. Accordingly, the suggested rule of the mixture is proposed as Equation 10.

$$
\mathrm{P}(\mathrm{z})=\mathrm{P}_{\mathrm{m}}-\mathrm{P}_{\mathrm{m}} \beta\left(\frac{\mathrm{z}}{\mathrm{h}}+\frac{1}{2}\right)^{\mathrm{k}}
$$

In the case of a homogenous plate $(\beta=0)$, for the imperfect FGM plate, Young's modulus (E) and material density $(\rho)$ equations can be expressed as Equations 11 and 12.

$$
\begin{aligned}
& E(z)=E_{m}-E_{m} \beta\left(\frac{z}{h}+\frac{1}{2}\right)^{k} \\
& \rho(z)=\rho_{m}-\rho_{m} \beta\left(\frac{z}{h}+\frac{1}{2}\right)^{k}
\end{aligned}
$$

To verify the proposed mathematical models (Equations $11 \& 12$ ) used for approximating material properties of imperfect FGM plates, this can be accomplished by comparisons between material property results secured directly from volume fraction analysis and the proposed models. Consider that the FGM plate made from Aluminum (Al) as porous metal whose material properties are: $E_{m}=70 \mathrm{GPa}, \rho=2702 \mathrm{Kg} / \mathrm{m}^{3} ; \mathrm{v}=0.3$ (Wattanasakulpong and Chaikittiratana, 2015). Table 1 shows the values of mass per unit length of the FGM plate.

From the comparisons in Table 1, it can be seen that the results predicted by the proposed models match well with those obtained from the volume fraction analysis. Additionally, to predict Young's modulus (E) across the plate thickness, Figure 2 shows the material properties profile of the imperfect FGM plates using Equations 11 and 12. 
Table 1

Two different techniques used to calculate the mass density of perfect and imperfect cores

\begin{tabular}{llll}
\hline $\mathrm{k}$ & Material & $\begin{array}{l}\text { Volume fraction } \\
\text { analysis } \\
\text { Mass }=\rho * \mathrm{~V}_{\mathrm{p}}\end{array}$ & $\begin{array}{l}\text { The proposed models } \\
\text { (Equation 12) }\end{array}$ \\
\hline $1,2 \ldots \ldots . \mathrm{n}$ & $\begin{array}{l}\text { Perfect FGM }(\beta=0), \\
\mathrm{Vp}=1\end{array}$ & $2700 * 1=2700$ & 2700 \\
& $\begin{array}{l}\text { Imperfect FGM, }(\beta \\
=0.1), \mathrm{Vp}=1-0.1=0.9\end{array}$ & $2700 * 0.9=2430$ & $2700-700 * 0.1=2430$ \\
& $\begin{array}{l}\text { Imperfect FGM, } \\
(\beta=0.2), \mathrm{Vp}=1-0.2=0.8\end{array}$ & $2700 * 0.8=2160$ & $2700-0.2 * 2700=2160$ \\
& $\begin{array}{l}\text { Imperfect FGM, } \\
(\beta=0.3), \mathrm{Vp}=1-0.3=0.7\end{array}$ & $2700 * 0.7=1890$ & $2700-0.3 * 2700=1890$ \\
& $\begin{array}{l}\text { Imperfect } \mathrm{FGM}, \\
(\beta=0.4), \mathrm{Vp}=1-0.4=0.6\end{array}$ & $2700 * 0.6=1620$ & $2700-0.4 * 2700=1620$ \\
& $\begin{array}{l}\text { Imperfect } \mathrm{FGM}, \\
(\beta=0.5), \mathrm{Vp}=1-0.5=0.5\end{array}$ & $2700 * 0.5=1350$ & $2700-0.5 * 2700=1350$ \\
\hline
\end{tabular}

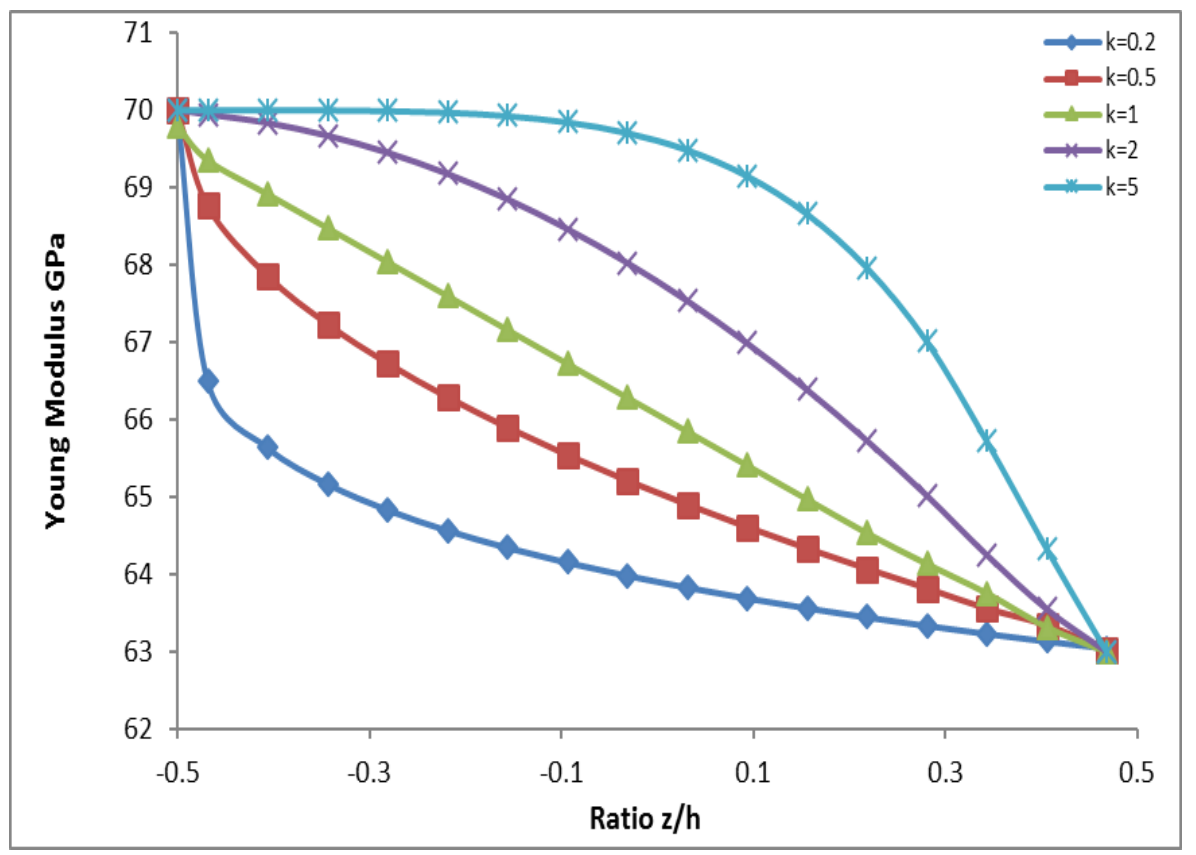

a) The modulus of elasticity (E) variation 


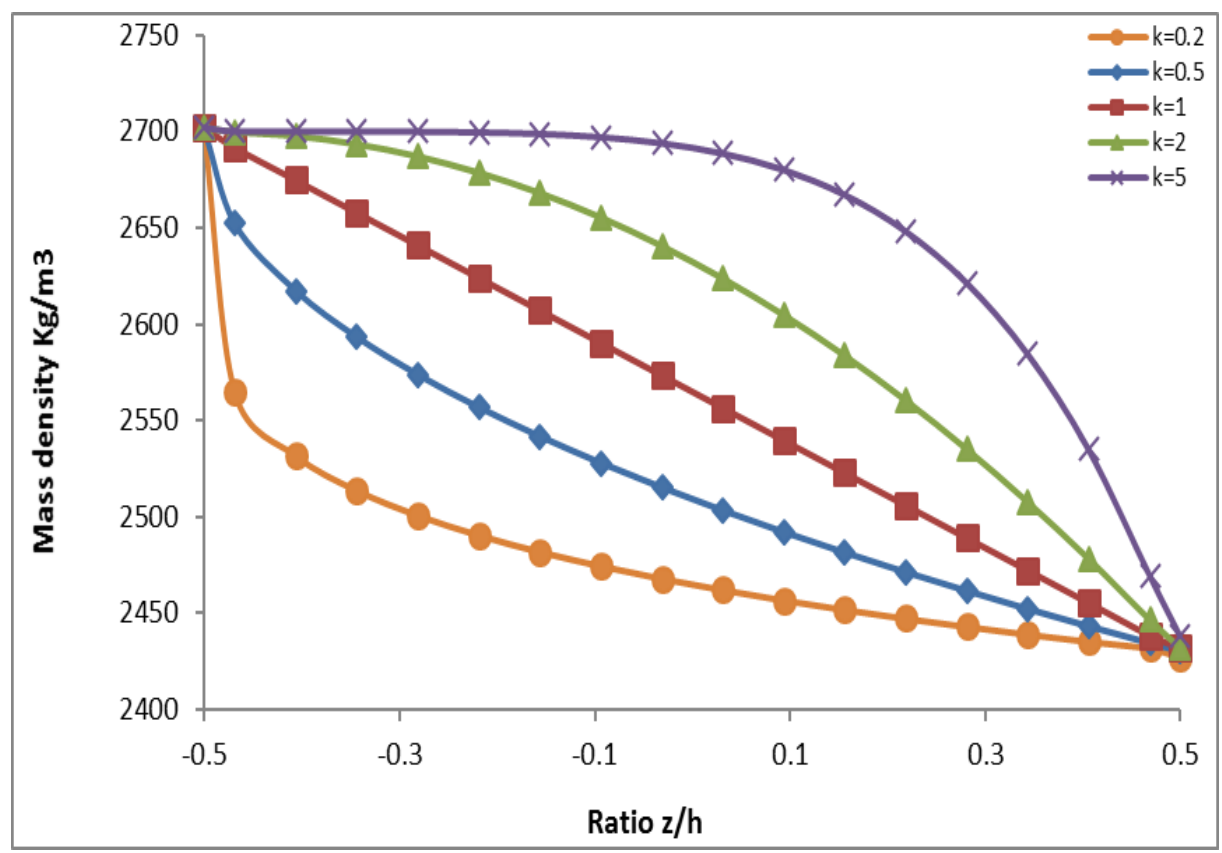

(b) The mass densities $(\rho)$ variation

Figure 2. Power-law variation at porosity $10 \%$ of (a) Young's modulus and (b) mass densities of the FG plate.

By using the CPT principle, the equations of motion that are convenient for the displacement components mentioned in Equation 5, including stiffness and inertia for vibration analysis of FGM plate, can be written as Equations 13-15:

$$
\begin{aligned}
& \mathrm{D}=\frac{1}{1-\mathrm{v}^{2}} \int_{-\mathrm{h} / 2}^{\mathrm{h} / 2} \mathrm{E}(\mathrm{z}) \cdot \mathrm{z}^{2} \mathrm{dz} \\
& \mathrm{D}_{\mathrm{f}}=\frac{\mathrm{E}_{\mathrm{p}} \mathrm{h}^{3}}{12\left(1-\mathrm{v}^{2}\right)}-\frac{\beta \mathrm{E}_{\mathrm{p}} \mathrm{h}^{3}}{\left(1-\mathrm{v}^{2}\right)}\left(\frac{1}{(\mathrm{k}+3)}-\frac{1}{(\mathrm{k}+2)}+\frac{1}{4(\mathrm{k}+1)}\right) \\
& \mathrm{I}_{\mathrm{o}}=\int_{-\mathrm{h} / 2}^{\mathrm{h} / 2} \rho(\mathrm{z}) \mathrm{dz}=\rho_{\mathrm{p}} \mathrm{h}\left\{1-\frac{\beta}{(\mathrm{k}+1)}\right\}
\end{aligned}
$$

Where, $\rho_{\mathrm{p}}$ and $\mathrm{E}_{\mathrm{p}}$ are the mass density and young modulus of the porous metal, respectively (Equation 16 \& 17).

$$
D_{f}\left(\frac{\partial^{4} w}{\partial x^{4}}+2 \frac{\partial^{4} w}{\partial x^{2} \cdot \partial y^{2}}+\frac{\partial^{4} w}{\partial y^{4}}\right)+I_{0} \frac{\partial^{2} w}{\partial t^{2}}=0
$$




$$
\begin{aligned}
& \left(\frac{E_{p} h^{3}}{12\left(1-v^{2}\right)}-\frac{\beta E_{p} h^{3}}{\left(1-v^{2}\right)}\left(\frac{1}{(k+3)}-\frac{1}{(k+2)}+\frac{1}{4(k+1)}\right)\right)\left(\frac{\partial^{4} w}{\partial x^{4}}+2 \frac{\partial^{4} w}{\partial x^{2} \cdot \partial y^{2}}+\frac{\partial^{4} w}{\partial y^{4}}\right) \\
& +\left(\rho_{p} h\left\{1-\frac{\beta}{(k+1)}\right\}\right) \frac{\partial^{2} w}{\partial t^{2}}=0
\end{aligned}
$$

Equation 17 can be solved by using the separation of the variables method by assuming the function of deflection as defined in Equation 18 (Al-Waily et al., 2020).

$$
w(x, y, t)=w(x, y) \cdot w(t)
$$

Where, $w(t)$ is the deflection function of the plate to time, and $w(x, y)$ is the deflection function of the sandwich in terms of $\mathrm{x}$ and $\mathrm{y}$ directions for a simply supported plate. Consider a rectangular plate of length $a$ and width $b$ with its four edges simply supported, as shown in Figure 2. To evaluate the behavior of deflection plate as a function of $x$ and $y$ directions that satisfies the boundary conditions $\mathrm{w}=0$ and $\mathrm{M}=0$; for all four edges, then, for the deflection equation of plate as a function of $\mathrm{x}$ and $\mathrm{y}$ direction, as Equation 19 (Leissa, 1969).

$$
w(x, y)=\sin \frac{m \pi x}{a} \cdot \sin \frac{n \pi y}{b}(m, n=1,2,3 \ldots \ldots \ldots)
$$

Then, by substituting Equation 17 into Equation 19, the suggested general equation of motion for FGM rectangular plate is obtained as Equation 20.

$$
\begin{aligned}
& \frac{E_{p} h^{3}}{12\left(1-v^{2}\right)}-\frac{\beta E_{p} h^{3}}{\left(1-v^{2}\right)}\left(\begin{array}{l}
\frac{1}{(k+3)}-\frac{1}{(k+2)} \\
+\frac{1}{4(k+1)}
\end{array}\right)\left(\begin{array}{l}
\left(\frac{\pi}{a}\right)^{4}++\left(\frac{\pi}{b}\right)^{4} \\
2 \times\left(\frac{\pi}{a}\right)^{2}\left(\frac{\pi}{b}\right)^{2}
\end{array}\right) \omega(t) \\
& +\rho_{p} h\left(1-\frac{\beta}{(k+1)}\right) \frac{\partial^{2} \omega}{\partial t^{2}}=0
\end{aligned}
$$

Equation 20 is a second-order ordinary differential equation. By comparison, Equation 20 with the general equation of motion of a single degree of freedom for free undamped vibration structure, as Equation 21 (Natarajan \& Manickam, 2012).

$$
\omega_{m n}^{2} w(t)+\frac{\partial^{2} w(t)}{\partial t^{2}}=0
$$

The suggested equation of natural frequency for FGM rectangular plate can find the natural frequency as Equations 22 and 23.

$$
\omega=h\left(\frac{\mathrm{A}_{\mathrm{o}}\left(\frac{\pi}{\mathrm{a}}\right)^{4}+2 \mathrm{~A}_{\mathrm{o}}\left(\frac{\pi}{\mathrm{a}}\right)^{2}\left(\frac{\pi}{\mathrm{b}}\right)^{2}+\mathrm{A}_{\mathrm{o}}\left(\frac{\pi}{\mathrm{b}}\right)^{4}}{\rho_{\mathrm{p}}\left(1-\frac{\beta}{(\mathrm{k}+1)}\right)}\right)^{1 / 2}
$$




$$
A_{o}=\frac{E_{p}}{12\left(1-v^{2}\right)}-\frac{\beta E_{p}}{\left(1-v^{2}\right)}\left(\frac{1}{k+3}-\frac{1}{k+2}+\frac{1}{4(k+1)}\right)
$$

The dimensionless fundamental frequencies $\psi$ for simply supported FGM square plate can be found as Equation 24.

$$
\psi=\frac{\omega L^{2}}{h} \sqrt{\frac{\int_{-h / 2}^{h / 2} \rho(z) d z}{\int_{-h / 2}^{h / 2} E(z) d z}}=\frac{\omega L^{2}}{h} \sqrt{\frac{\rho_{p}}{E_{p}}}
$$

\section{Modeling Analysis for FGM Sandwich Plate with FGM Porous Metal Core}

FGM sandwich plates are usually represented either in face sheet FGM and uniform core or uniform face sheet with FGM core. In this paper, the second type (sandwich plates with uniform skin and core FGM) is considered and analyzed to study the frequency response of FGM sandwich plates with different boundary conditions. The volume fraction of the FGM sandwich pate is assumed as Equation 25 (Cui et al., 2019).

$$
\begin{aligned}
& V_{1}(z)=0, z \in\left[h_{1}, h_{2}\right] \\
& V_{2}(z)=\left(\frac{z-h_{2}}{h_{3}-h_{2}}\right)^{k}, z \in\left[h_{2}, h_{3}\right] \\
& V_{3}(z)=1, z \in\left[h_{3}, h_{4}\right]
\end{aligned}
$$

For the material characteristics of FGM plate with porosity, they considered to vary continuously within the thickness of the plate according to the power-law distribution $(\mathrm{k})$, $(\beta)$ : is the factor of the distribution of the porosity according to the plate thickness, hence for the even distribution of porosities inside the material, the young's modulus E (z) and mass density $\rho(z)$ of the imperfect FGM plate represented as given in Equations 13 and 14 , respectively.

Consider a sandwich plate of length $a$ and width $b$ with its four edges simply supported, comprise mainly from Porous metal core is considered as a functionally graded material owing to the variation of porous ratio inside the core metal while the upper and lower plate, both of them made of same homogenous material as shown in Figure 3, so the elastic constants $E_{U P}=E_{L P}, v_{U P}=v_{L P}=v$ and the mass density $\rho_{U P}=\rho_{L P}$.

To derive the governing differential equation of motion of sandwich panels with an FGM core, Equations 5 and 6 are applied for each layer of the sandwich plate (upper face, core, and lower face), and reassemble them to Equation 11 as it will be discussed in the previous section. Assuming $h_{U P}=h_{L P}$, the general representation for the flexural rigidity and inertia for the sandwich plate $\left(D_{\mathrm{SP}}\right.$ and $\left.I_{\mathrm{SP}}\right)$ can be written as Equations 26-28. 


$$
\begin{aligned}
& \mathrm{D}_{\mathrm{SP}}=\left(\begin{array}{l}
\left.\int_{-\left(\frac{\mathrm{h}_{\mathrm{FG}}}{2}+\mathrm{h}_{\mathrm{LP}}\right)}^{-\frac{\left.\mathrm{h}_{\mathrm{FG}}\right)}{2}}\left\{\frac{\mathrm{z}^{2}}{\left(1-\mathrm{v}_{\mathrm{LP}}^{2}\right)} \mathrm{E}(\mathrm{z})\right\} d z+\int_{\left(\frac{\mathrm{h}_{\mathrm{FG}}}{2}\right)}^{\left(\frac{\mathrm{h}_{\mathrm{FG}}}{2}+\mathrm{h}_{\mathrm{UP}}\right)}\left\{\frac{\mathrm{z}^{2}}{\left(1-\mathrm{v}_{\mathrm{UP}}^{2}\right)} \mathrm{E}(\mathrm{z})\right\} d z\right) \\
\left.\left.+\frac{1}{\left(1-\mathrm{v}_{\mathrm{FG}}^{2}\right)}\left(\int_{-\left(\frac{\mathrm{h}_{\mathrm{FG}}}{2}\right)}^{\left(\frac{\mathrm{h}_{\mathrm{FG}}}{2}\right)} \mathrm{E}_{\mathrm{p}}-\beta \mathrm{E}_{\mathrm{p}}\left(\frac{\mathrm{z}}{\mathrm{h}}+\frac{1}{2}\right)^{\mathrm{k}}\right)\right\} \mathrm{z}^{2}\right) d z
\end{array}\right) \\
& +\frac{\mathrm{E}_{\mathrm{p}} \mathrm{h}^{3}}{12\left(1-\mathrm{v}^{2}\right)}-\frac{\beta \mathrm{E}_{\mathrm{P}} \mathrm{h}^{3}}{\left(1-\mathrm{v}^{2}\right)}\left(\frac{1}{(\mathrm{k}+3)}-\frac{1}{(\mathrm{k}+2)}+\frac{1}{4(\mathrm{k}+1)}\right) \\
& \mathrm{I}_{\mathrm{SP}}=\rho_{\mathrm{p}} \mathrm{v}_{\mathrm{FG}}\left\{\frac{2\left(\frac{\mathrm{h}_{\mathrm{FG}}}{2}+\mathrm{h}_{\mathrm{UP}}\right)^{3}}{3}-\frac{\mathrm{h}_{\mathrm{FG}}^{3}}{12}\right) \\
& \left.\frac{\beta}{(\mathrm{k}+1)}\right\}+2 \rho \mathrm{h}_{\mathrm{UP}}
\end{aligned}
$$
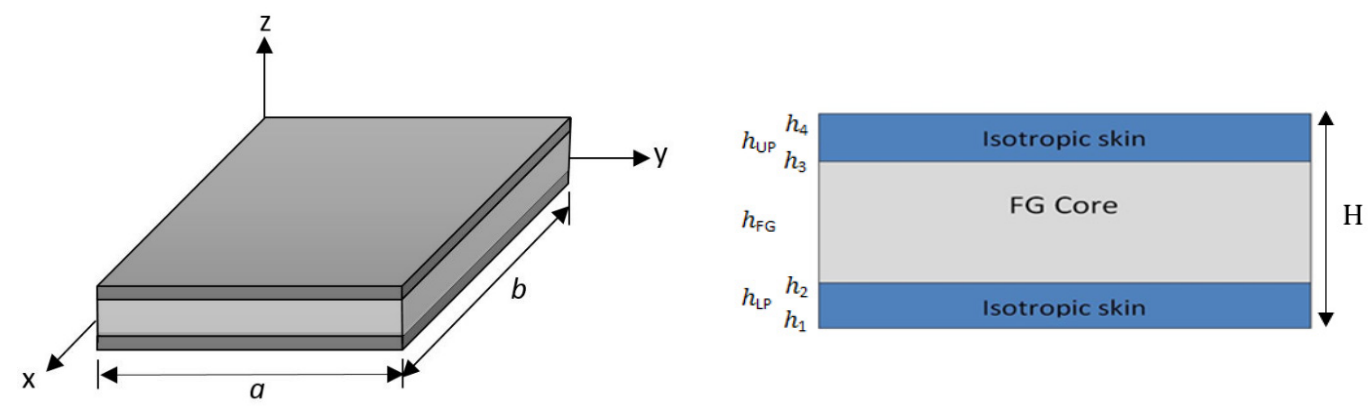

Figure 3. Geometry configurations of FGM porous sandwich plate

To evaluate the natural frequency of the sandwich plate follows the same procedure mentioned in the rectangular plate in Equation 21 to obtain Equation 29.

$$
\omega=2\left(\frac{\pi}{\mathrm{a}}\right)^{2}\left(\frac{\mathrm{C}(\mathrm{k}+1)}{\rho_{\mathrm{p}} \mathrm{h}_{\mathrm{FG}}\{\mathrm{k}+1-\beta\}+2 \rho \mathrm{h}_{\mathrm{UP}}(\mathrm{k}+1)}\right)^{1 / 2}
$$

To simplify (Equation 30),

$$
\begin{aligned}
& \mathrm{C}=\frac{\mathrm{E}_{\mathrm{p}} \mathrm{h}_{\mathrm{FG}}^{3}}{12\left(1-\mathrm{v}^{2}\right)}-\frac{\beta \mathrm{E}_{\mathrm{p}} \mathrm{h}_{\mathrm{FG}}^{3}}{\left(1-\mathrm{v}^{2}\right)}\left(\frac{1}{(\mathrm{k}+3)}-\frac{1}{(\mathrm{k}+2)}+\frac{1}{4(\mathrm{k}+1)}\right) \\
& +\frac{\mathrm{E}_{\mathrm{UP}}}{\left(1-\mathrm{v}_{\mathrm{UP}}^{2}\right)}\left(\frac{2\left(\frac{\mathrm{h}_{\mathrm{FG}}}{2}+\mathrm{h}_{\mathrm{UP}}\right)^{3}}{3}-\frac{\mathrm{h}_{\mathrm{FG}}^{3}}{12}\right)
\end{aligned}
$$




\section{Numerical Investigation}

The accuracy of the suggested analytical solution can be verified by employ numerical methods. Many numerical techniques are used to solve problems (Sadiq et al. 2020), but the most accurate is the FEA method (Reddy, 1993; Rao, 2004). In this work, the finite element method represented by the ANSYS program (Ver. 2020 R2) was used. A 3D model of the FG sandwich plate is built and the corresponding boundary conditions of the sides of the plate under modal analysis are applied as shown in Figure 4. The precision mesh size is selected and the model has meshed with an 8-node SOLID186 element type with a total number of elements 40000 as shown in Figure 5. The mechanical properties of the FG core are calculated using Equations 11 and 12, while the skin parts are assumed isotropic materials, then inserted into the examined model. In the connection area between the layers and between the layers and the sandwich plat's skin, glue regulations should be made to prevent the development of the pedigree between the layers from respecting each other (Burlayenko \& Sadowski, 2020). The modal analysis for the selected models is carried out to identify the free vibration characteristics (natural frequencies and the mode shapes) based on various parameters previously mentioned as shown in Figure 6.

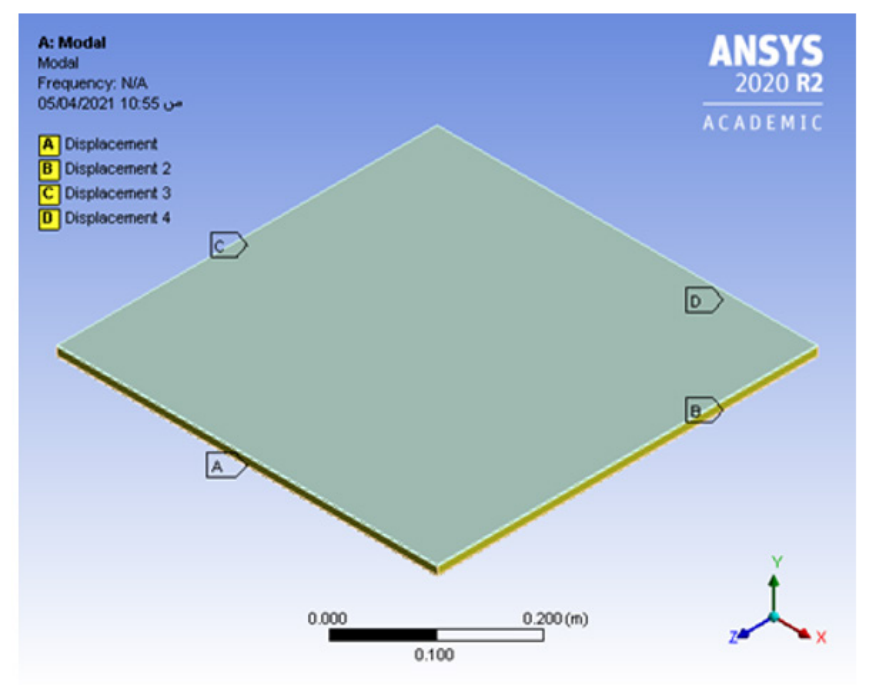

Figure 4. FGM Sandwich plate 


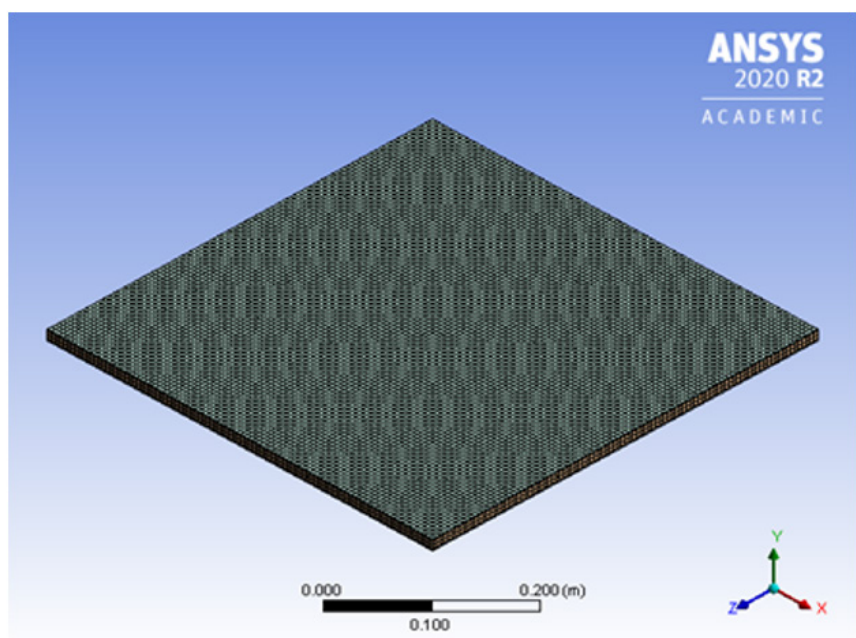

Figure 5. Meshed Model

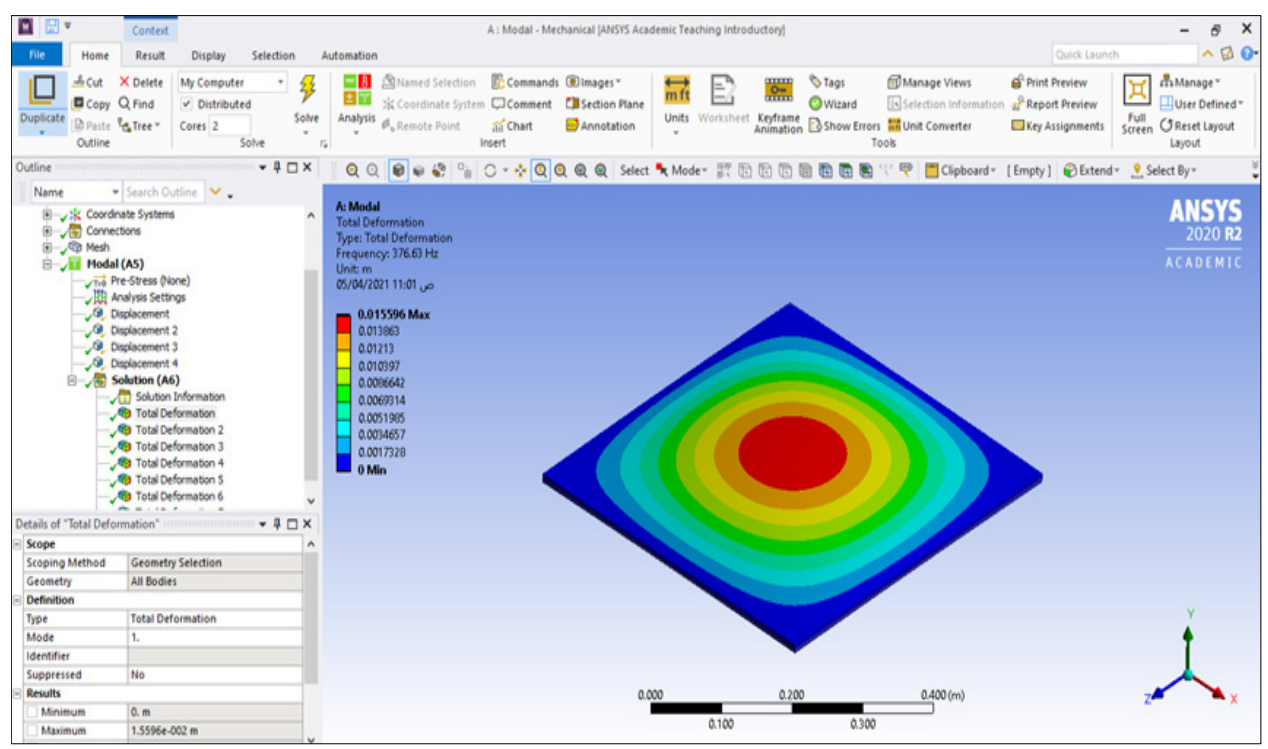

Figure 6. View of Modal Analysis of FGM sandwich plate

\section{RESULTS AND DISCUSSION}

In this work, a new mathematical model was derived to evaluate the free vibration characteristics of power-law simply supported FGM rectangular sandwich plates with even porosity distribution. Effects of various properties on frequency parameters are 
investigated. The FGM part is composed of a porous metal core with volume fractions that change smoothly through the thickness direction. The natural frequencies are presented for the various metal cores types with a power-law variation. The commercially available software of ANSYS 2020 R2 was also used for verification of the analytical solution, and the obtained results were tabulated and plotted with multiple curves. The material characteristics of the FG core are presented in Table 2, simultaneously, the face sheet is considered made of Aluminum with a mass density of $2702 \mathrm{Kg} / \mathrm{m}^{3}$ and a modulus of elasticity of $70 \mathrm{GPa}$. The dimensions of plates are taken as $a=\mathrm{b}=0.5 \mathrm{~m}$, the power-law distribution $(k=0,0.5,1,2,5,10,50,100)$ and porosity factor $(\beta=0$ to 0.4$)$, the face sheet thickness is $(1,1.5,2$ and 2.5) $\mathrm{mm}$ and FG core heights $(5,6,8,10,12,20$, and 25) $\mathrm{mm}$.

Table 2

Material properties of the FG core

\begin{tabular}{|c|c|c|c|c|}
\hline FG core type & $\begin{array}{l}\text { Modula's of } \\
\text { Elasticity (MPa) }\end{array}$ & $\begin{array}{l}\text { Mass Density } \\
\mathrm{Kg} / \mathrm{m}^{3}\end{array}$ & $\begin{array}{l}\text { Poison's } \\
\text { Ratio }\end{array}$ & Ref. \\
\hline Polyethylene & 1100 & 950 & 0.42 & (Liu et al., 2015) \\
\hline Peek - $30 \%$ CF & 7700 & 1410 & 0.44 & $\begin{array}{l}\text { (Bonnheim et al., } \\
\text { 2019) }\end{array}$ \\
\hline Peek - $30 \%$ GF & 6300 & 1510 & 0.34 & $\begin{array}{l}\text { (Najim \& Adwaa, } \\
\text { 2014) }\end{array}$ \\
\hline $\begin{array}{l}\text { Peek }-1000 \\
\text { natural }\end{array}$ & 4400 & 1310 & 0.40 & $\begin{array}{l}\text { (Najim \& Adwaa, } \\
\text { 2014) }\end{array}$ \\
\hline $\begin{array}{l}\text { Polyurethane } \\
\text { foam }\end{array}$ & 7.5 & 60 & 0 & (Goel et al., 2013) \\
\hline Foam Dytherm & 3.0 & 100 & 0 & (Goel et al., 2013) \\
\hline
\end{tabular}

To verify the accuracy of the suggested mathematical model in predicting the natural frequency of FG sandwich plates. Natural frequencies for the sandwich plate with various parameters such as aspect ratio, slenderness ratio, porous factor, FG core thickness, and face sheet thickness are presented in Tables 3-5. Once the natural frequency from Equation 30 has been worked out, the fundamental frequency parameter of a simply supported square FGM sandwich plates with porous FG core with different thickness ratio can be calculated from the following Equation 31.

$$
\psi=\frac{\omega L^{2}}{h} \sqrt{\frac{\rho_{o}}{E_{0}}}
$$

Where, $\omega$ is the natural frequency, $L$ is the length of the plate and $h$ is the total height of the sandwich plate. Suppose that $\rho_{0}=1 \mathrm{Kg} / \mathrm{m}^{3}$ and $E_{0}=1 \mathrm{MPa}$. Table 3 present analytical and 
numerical results for the first nondimensional frequencies of the sandwich plate for various porosity parameters $(\beta=0.1,0.2,0.3$, and 0.4$)$, power-law indices $(\mathrm{k}=0,0.5,1,2$, and 5$)$, and face sheet thickness $(1,1.5,2$ and $2.5 \mathrm{~mm})$ for the FG core metal made of Polyethylene FGM core thickness $10 \mathrm{~mm}$. Data shows that the core topology has a significant role in the frequency parameters as represented in Table 3-5. Fair agreements are found between analytical tests and numerical analyses with a difference of less than $8 \%$. Table 4 gives results obtained by the analytical solution and FEA of the nondimensional frequency of rectangular sandwich plate with FG Polyethylene core, (FG core thickness $12 \mathrm{~mm}$ ) with various porosity factors $(\beta=0.1,0.2,0.3$, and 0.4$)$, volume fraction index $(k=0,0.5,1,2$, and 5 ) and by using five values of aspect ratio ( $a / b=0.25,0.5,0.75,1$ and 2 ).

It can also be seen that the natural frequencies decrease with increasing gradient index and increase the porous parameter due to the decrease in the material rigidity. An excellent agreement can be observed with a difference of up to $8 \%$, and this percentage is affected by the power-law index and porous factor for the same FG plate thickness. Convergence of the non-dimensional frequencies of square FGM sandwich plate with Polyethylene porous core and aluminum face sheet $(2 \mathrm{~mm})$, subject to seven combinations of boundary conditions is presented in Table 5 with respect to thickness ratio $(a / H=50)$ and various porosity factors. It is found that the value of frequency parameter increases with an increase in the number of constraints of the selected model; for example, at porous factor $(\beta=0.3)$ and with a gradient index $(\mathrm{k}=2)$, the frequency parameter in the CCCC model is (6.523) while for CCCS it was (6.027), and CSCS equal (5.825), as for SSSS, the value was (5.436), for CCCF edge condition the frequency parameter became (3.894), while for FCFC and FSFS, the frequency parameter was (3.626) and (2.827) respectively.

Table 3

The frequency parameter ( $\psi$ ) of the sandwich plate with Polyethylene FGM core thickness $10 \mathrm{~mm}$

\begin{tabular}{|c|c|c|c|c|c|c|c|c|c|}
\hline \multirow{3}{*}{$\begin{array}{l}\text { porosity } \\
\%\end{array}$} & \multirow{3}{*}{$\begin{array}{l}\text { power- } \\
\text { law } \\
\text { index } \\
\text { (k) }\end{array}$} & \multicolumn{8}{|c|}{ face sheet thickness (mm) } \\
\hline & & \multicolumn{2}{|c|}{1} & \multicolumn{2}{|c|}{1.5} & \multicolumn{2}{|c|}{2} & \multicolumn{2}{|c|}{2.5} \\
\hline & & Ana. & Num. & Ana. & Num. & Ana. & Num. & Ana. & Num. \\
\hline \multirow[t]{5}{*}{10} & 0 & 4.645 & 4.638 & 5.158 & 5.139 & 5.415 & 5.531 & 5.531 & 5.531 \\
\hline & 0.5 & 4.595 & 4.601 & 5.111 & 5.109 & 5.372 & 5.371 & 5.493 & 5.502 \\
\hline & 1 & 4.571 & 4.569 & 5.088 & 5.067 & 5.351 & 5.361 & 5.474 & 5.484 \\
\hline & 2 & 4.546 & 4.550 & 5.065 & 5.060 & 5.330 & 5.355 & 5.455 & 5.466 \\
\hline & 5 & 4.523 & 4.534 & 5.042 & 5.039 & 5.309 & 5.313 & 5.436 & 5.442 \\
\hline
\end{tabular}


Table 3 (Continued)

\begin{tabular}{|c|c|c|c|c|c|c|c|c|c|}
\hline \multirow{3}{*}{$\begin{array}{l}\text { porosity } \\
\%\end{array}$} & \multirow{3}{*}{$\begin{array}{l}\text { power- } \\
\text { law } \\
\text { index } \\
(\mathrm{k})\end{array}$} & \multicolumn{8}{|c|}{ face sheet thickness (mm) } \\
\hline & & \multicolumn{2}{|c|}{1} & \multicolumn{2}{|c|}{1.5} & \multicolumn{2}{|c|}{2} & \multicolumn{2}{|c|}{2.5} \\
\hline & & Ana. & Num. & Ana. & Num. & Ana. & Num. & Ana. & Num. \\
\hline \multirow[t]{5}{*}{20} & 0 & 4.806 & 4.810 & 5.308 & 5.340 & 5.550 & 5.489 & 5.652 & 5.691 \\
\hline & 0.5 & 4.697 & 4.690 & 5.207 & 5.225 & 5.459 & 5.431 & 5.571 & 5.588 \\
\hline & 1 & 4.645 & 4.651 & 5.158 & 5.188 & 5.415 & 5.386 & 5.531 & 5.506 \\
\hline & 2 & 4.594 & 4.589 & 5.110 & 5.092 & 5.371 & 5.297 & 5.492 & 5.477 \\
\hline & 5 & 4.546 & 4.553 & 5.064 & 5.078 & 5.329 & 5.245 & 5.454 & 5.382 \\
\hline \multirow[t]{5}{*}{30} & 0 & 4.986 & 4.978 & 5.472 & 5.511 & 5.696 & 5.680 & 5.782 & 5.219 \\
\hline & 0.5 & 4.807 & 4.911 & 5.308 & 5.479 & 5.550 & 5.622 & 5.652 & 5.145 \\
\hline & 1 & 4.724 & 4.696 & 5.231 & 5.099 & 5.481 & 5.579 & 5.5917 & 4.988 \\
\hline & 2 & 4.644 & 4.674 & 5.157 & 4.888 & 5.414 & 5.515 & 5.531 & 4.866 \\
\hline & 5 & 4.569 & 4.552 & 5.086 & 4.857 & 5.350 & 5.464 & 5.473 & 4.770 \\
\hline \multirow[t]{5}{*}{40} & 0 & 5.189 & 5.226 & 5.653 & 5.714 & 5.855 & 5.776 & 5.921 & 5.887 \\
\hline & 0.5 & 4.925 & 5.0996 & 5.416 & 5.686 & 5.646 & 5.681 & 5.738 & 5.686 \\
\hline & 1 & 4.806 & 4.947 & 5.308 & 5.562 & 5.550 & 5.590 & 5.652 & 5.450 \\
\hline & 2 & 4.696 & 4.775 & 5.205 & 5.441 & 5.458 & 5.422 & 5.570 & 5.499 \\
\hline & 5 & 4.593 & 4.694 & 5.109 & 5.215 & 5.370 & 5.299 & 5.492 & 5.456 \\
\hline
\end{tabular}

Table 4

Analytical and Numerical results of the frequency parameter of the rectangular FG sandwich plate with Polyethylene core thickness $12 \mathrm{~mm}$

\begin{tabular}{|c|c|c|c|c|c|c|c|c|c|}
\hline \multirow[t]{3}{*}{$\mathrm{a} / \mathrm{b}$} & \multirow{3}{*}{$\begin{array}{l}\text { power- } \\
\text { law index } \\
(\mathrm{k})\end{array}$} & \multicolumn{8}{|c|}{ porosity factor $(\beta)$} \\
\hline & & \multicolumn{2}{|l|}{0.1} & \multicolumn{2}{|c|}{0.2} & \multicolumn{2}{|c|}{0.3} & \multicolumn{2}{|c|}{0.4} \\
\hline & & Ana. & Num. & Ana. & Num. & Ana. & Num. & Ana. & Num. \\
\hline \multirow[t]{5}{*}{0.25} & 0 & 3.2 & 3.3 & 3.3 & 3.3 & 3.4 & 3.4 & 3.5 & 3.5 \\
\hline & 0.5 & 3.2 & 3.2 & 3.2 & 3.3 & 3.3 & 3.4 & 3.4 & 3.5 \\
\hline & 1 & 3.2 & 3.2 & 3.2 & 3.3 & 3.3 & 3.3 & 3.3 & 3.4 \\
\hline & 2 & 3.2 & 3.2 & 3.2 & 3.2 & 3.2 & 3.3 & 3.2 & 3.3 \\
\hline & 5 & 3.1 & 3.1 & 3.2 & 3.2 & 3.2 & 3.2 & 3.2 & 3.3 \\
\hline
\end{tabular}


Table 4 (Continued)

\begin{tabular}{|c|c|c|c|c|c|c|c|c|c|}
\hline \multirow[t]{3}{*}{$a / b$} & \multirow{3}{*}{$\begin{array}{l}\text { power- } \\
\text { law index } \\
(\mathrm{k})\end{array}$} & \multicolumn{8}{|c|}{ porosity factor $(\beta)$} \\
\hline & & \multicolumn{2}{|l|}{0.1} & \multicolumn{2}{|c|}{0.2} & \multicolumn{2}{|c|}{0.3} & \multicolumn{2}{|c|}{0.4} \\
\hline & & Ana. & Num. & Ana. & Num. & Ana. & Num. & Ana. & Num. \\
\hline \multirow[t]{5}{*}{0.5} & 0 & 3.8 & 3.8 & 3.9 & 3.8 & 4.0 & 4.1 & 4.1 & 4.1 \\
\hline & 0.5 & 3.8 & 3.7 & 3.8 & 3.8 & 3.9 & 4.0 & 4.0 & 4.1 \\
\hline & 1 & 3.7 & 3.7 & 3.8 & 3.8 & 3.8 & 3.9 & 3.9 & 3.9 \\
\hline & 2 & 3.7 & 3.7 & 3.8 & 3.8 & 3.8 & 3.8 & 3.8 & 3.9 \\
\hline & 5 & 3.7 & 3.7 & 3.7 & 3.7 & 3.7 & 3.7 & 3.8 & 3.9 \\
\hline \multirow[t]{5}{*}{0.75} & 0 & 4.7 & 4.8 & 4.9 & 4.9 & 5.0 & 5.3 & 5.2 & 5.1 \\
\hline & 0.5 & 4.7 & 4.7 & 4.8 & 4.8 & 4.9 & 5.1 & 5.0 & 4.8 \\
\hline & 1 & 4.7 & 4.7 & 4.7 & 4.8 & 4.8 & 4.9 & 4.9 & 4.8 \\
\hline & 2 & 4.6 & 4.7 & 4.7 & 4.8 & 4.7 & 4.8 & 4.8 & 4.7 \\
\hline & 5 & 4.6 & 4.6 & 4.6 & 4.7 & 4.7 & 4.7 & 4.7 & 4.7 \\
\hline \multirow[t]{5}{*}{1} & 0 & 6.1 & 6.1 & 6.2 & 6.3 & 6.4 & 6.6 & 6.6 & 6.6 \\
\hline & 0.5 & 6.0 & 6.1 & 6.1 & 6.3 & 6.2 & 6.5 & 6.3 & 6.4 \\
\hline & 1 & 6.0 & 5.9 & 6.1 & 6.2 & 6.1 & 6.4 & 6.2 & 6.3 \\
\hline & 2 & 6.0 & 5.9 & 6.0 & 6.1 & 6.1 & 6.1 & 6.1 & 6.2 \\
\hline & 5 & 5.9 & 5.8 & 5.9 & 5.9 & 6.0 & 6.1 & 6.0 & 6.0 \\
\hline \multirow[t]{5}{*}{1.5} & 0 & 9.8 & 9.9 & 10.1 & 10.0 & 10.4 & 10.5 & 10.7 & 10.7 \\
\hline & 0.5 & 9.8 & 9.8 & 9.9 & 10.0 & 10.1 & 10.2 & 10.3 & 10.5 \\
\hline & 1 & 9.7 & 9.8 & 9.8 & 9.9 & 10.0 & 10.0 & 10.1 & 10.1 \\
\hline & 2 & 9.7 & 9.5 & 9.8 & 9.8 & 9.8 & 9.9 & 9.9 & 10.0 \\
\hline & 5 & 9.6 & 9.5 & 9.7 & 9.7 & 9.7 & 9.8 & 9.8 & 9.8 \\
\hline \multirow[t]{5}{*}{2} & 0 & 15.1 & 15.1 & 15.6 & 15.4 & 16.0 & 15.9 & 16.5 & 16.6 \\
\hline & 0.5 & 15.0 & 15.1 & 15.3 & 15.2 & 15.6 & 15.6 & 15.9 & 16.2 \\
\hline & 1 & 14.9 & 15.1 & 15.1 & 15.1 & 15.3 & 15.5 & 15.6 & 15.9 \\
\hline & 2 & 14.9 & 15.0 & 15.0 & 15.0 & 15.1 & 15.1 & 15.3 & 15.7 \\
\hline & 5 & 14.8 & 15.0 & 14.9 & 14.9 & 14.9 & 15.0 & 15.0 & 15.3 \\
\hline
\end{tabular}


Table 5

Convergence of frequency parameters of square FG sandwich plate with Polyethylene core thickness 10mm, face sheet thickness $2.5 \mathrm{~mm}$, for different Boundary conditions

\begin{tabular}{|c|c|c|c|c|c|}
\hline \multirow[t]{2}{*}{ BC's } & \multirow{2}{*}{$\begin{array}{l}\text { power-law } \\
\text { index }(k)\end{array}$} & \multicolumn{4}{|c|}{ porosity factor $(\beta)$} \\
\hline & & 0.1 & 0.2 & 0.3 & 0.4 \\
\hline \multirow[t]{6}{*}{$\mathrm{CCCC}$} & 0 & 6.959 & 7.017 & 7.141 & 7.511 \\
\hline & 0.5 & 7.229 & 7.124 & 7.185 & 7.420 \\
\hline & 1 & 7.094 & 6.796 & 7.262 & 7.129 \\
\hline & 2 & 6.799 & 7.390 & 6.523 & 7.287 \\
\hline & 5 & 6.826 & 6.584 & 6.878 & 7.227 \\
\hline & 10 & 7.081 & 6.882 & 7.163 & 6.909 \\
\hline \multirow[t]{6}{*}{ CSCS } & 0 & 6.247 & 6.322 & 6.404 & 6.760 \\
\hline & 0.5 & 6.483 & 6.395 & 6.592 & 6.667 \\
\hline & 1 & 6.373 & 6.092 & 6.261 & 6.422 \\
\hline & 2 & 6.125 & 6.646 & 5.825 & 6.536 \\
\hline & 5 & 6.133 & 6.040 & 6.007 & 6.488 \\
\hline & 10 & 6.359 & 6.189 & 6.367 & 5.906 \\
\hline \multirow[t]{6}{*}{ CCCS } & 0 & 6.013 & 6.204 & 6.358 & 6.487 \\
\hline & 0.5 & 5.988 & 6.066 & 6.172 & 6.270 \\
\hline & 1 & 5.960 & 6.030 & 6.083 & 6.168 \\
\hline & 2 & 6.049 & 5.998 & 6.027 & 6.049 \\
\hline & 5 & 5.813 & 5.969 & 5.971 & 5.992 \\
\hline & 10 & 6.016 & 5.942 & 5.931 & 5.927 \\
\hline \multirow[t]{9}{*}{ SSSS } & 0 & 5.437 & 5.569 & 5.713 & 5.868 \\
\hline & 0.5 & 5.395 & 5.480 & 5.570 & 5.664 \\
\hline & 1 & 5.374 & 5.437 & 5.502 & 5.569 \\
\hline & 2 & 5.353 & 5.394 & 5.436 & 5.479 \\
\hline & 5 & 5.333 & 5.353 & 5.373 & 5.393 \\
\hline & 10 & 5.324 & 5.3351 & 5.345 & 5.356 \\
\hline & 2 & 4.020 & 4.357 & 3.894 & 4.043 \\
\hline & 5 & 3.841 & 3.945 & 3.818 & 4.151 \\
\hline & 10 & 4.015 & 3.804 & 3.990 & 4.211 \\
\hline
\end{tabular}


Table 5 (Continued)

\begin{tabular}{llcccc}
\hline \multirow{2}{*}{ BC's } & power-law & \multicolumn{4}{c}{ porosity factor $(\beta)$} \\
\cline { 2 - 6 } index $(\mathrm{k})$ & 0.1 & 0.2 & 0.3 & 0.4 \\
\hline FCFC & 0 & 3.697 & 3.899 & 3.970 & 4.166 \\
& 0.5 & 3.749 & 3.644 & 3.954 & 3.965 \\
& 1 & 3.601 & 3.860 & 4.126 & 3.731 \\
& 2 & 3.688 & 4.046 & 3.626 & 3.726 \\
& 5 & 3.600 & 3.629 & 3.654 & 3.829 \\
& 10 & 3.700 & 3.468 & 3.704 & 3.910 \\
FSFS & 0 & 2.610 & 2.840 & 2.628 & 2.875 \\
& 0.5 & 2.428 & 3.014 & 2.618 & 2.747 \\
& 1 & 2.526 & 2.664 & 2.696 & 2.729 \\
& 2 & 2.248 & 2.320 & 2.827 & 2.520 \\
& 5 & 2.640 & 2.730 & 2.740 & 2.535 \\
& 10 & 3.993 & 2.507 & 2.496 & 2.517 \\
& 0 & 3.974 & 4.195 & 4.240 & 4.441 \\
& 0.5 & 4.124 & 3.972 & 4.310 & 4.270 \\
& 1 & 3.835 & 4.115 & 4.448 & 3.952 \\
& 2 & 4.020 & 4.357 & 3.894 & 4.043 \\
& 2 & 3.841 & 3.945 & 3.818 & 4.151 \\
& 5 & 4.015 & 3.804 & 3.990 & 4.211 \\
\hline
\end{tabular}

Graphical representations of the natural frequency relationships for simply supported FG sandwich plates given by Eqs. (29 and 30) are shown in Figures 7-16. Figure 7 shows the analytical results of the fundamental natural frequency of the sandwich plate of Polyethylene core porous meal at the porosity percentage $(\beta=10 \%)$, for various face sheet thicknesses $(1,1.5,2$, and $2.5 \mathrm{~mm})$ and the gradient index $(\mathrm{k}=0$ to 100$)$. It can be easily noticed that the natural frequency gradually decreases as the power-law exponent increases and increases as the slenderness ratio increases. Figure 8 shows the fundamental natural frequency at five slenderness ratios $(a / H=5,10,20,25,50$ and 100$)$ for porous metal comprise from Polyathelen at porosity factor $(\beta=0.1)$. From the results drawn in, it is concluded that when the frequencies are low (lower modes of frequency or thin plates) the suggested analytical solution by CPT is close to the numerical solutions, and when the plate thickness increases and for higher mode frequencies, the error percentage in CPT will be higher. Considering the influence of porous metal type, Figure 9 gives details of the analytical results of the natural frequency at porosity ratio $(\beta=10 \%)$, for various 
porous metals (PEEK 30\% CF, PEEK 30\% GF, Foam dythem, and Polyurethane foam) at core height $10 \mathrm{~mm}$ and face thickness $2.5 \mathrm{~mm}$. It is concluded that the Polyurethane foam has higher stiffness than foam Dythem and all Peek types, respectively, due to the high mechanical properties values. Figure 10 shows the analytical results of the natural frequency at porosity ratio $(\beta=10 \%)$, for various face sheet thicknesses $(1,1.5,2$, and 2.5 $\mathrm{mm}$ ) with FGM core height $5 \mathrm{~mm}$. Figure 11 plots variation of dimensionless frequencies of FGM rectangular plate at power-law index $(k=0.5)$, and porosity ratio $(\beta=10 \%)$ with different aspect ratios $(a / b=0.25,0.5,0.75,1$ and 2$)$. Figure 12 shows the analytical results of the natural frequency at porosity ratio $(\beta=10 \%)$, for various face sheet thicknesses and by using various core metals. Figure 13 shows the impact of number of the layers on the natural frequency of FGM rectangular plate at power-law index $(\mathrm{k}=0.5)$ and porosity ratio $(\beta=10 \%)$ for different aspect ratio $(a / b=0.25,0.5,0.75,1$ and 2$)$. It may also be viewed that frequency parameters are increasing with an increase in aspect ratios. The reason may be the rectangular sandwich plate is becoming stiffer gradually with an increase in aspect ratios. Figure 14 presents influences of the number of the layers on the natural frequency at different thickness ratios $(a / H=20,25,50$ and 100) of the square FGM sandwich plate at gradient index $(k=2)$ and porosity ratio $(\beta=10 \%)$. From Figure 14 , it is found that the natural frequency of plates increases with increasing the aspect ratios, and the effect of the number of layers must lower on frequency curve behavior. Figures 15 and 16 represent a 3D surface plot for variation of dimensionless natural frequencies of simply supported FG sandwich plate at different porous parameters, and various values of face sheet thickness, respectively. Accordingly, in Figure 17, the first six deflections of 3-D mode shapes are generated for simply supported FGM square sandwich plate at porosity ratio $(\beta=0.0 \%)$, gradient index $(k=0.5)$, and slenderness ratio $(a / h=50)$. In a similar fashion, it is also possible to display further 3D mode shapes supported by different edge conditions.

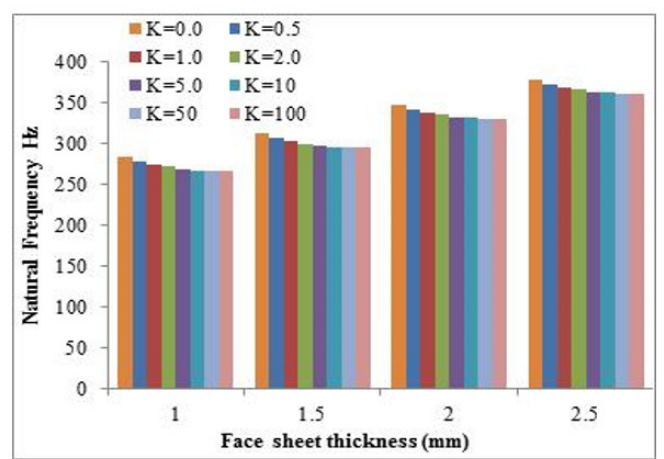

Figure 7. Results of the fundamental natural frequency at Beta $=0.2$, core height $12 \mathrm{~mm}$ for various gradient index values.

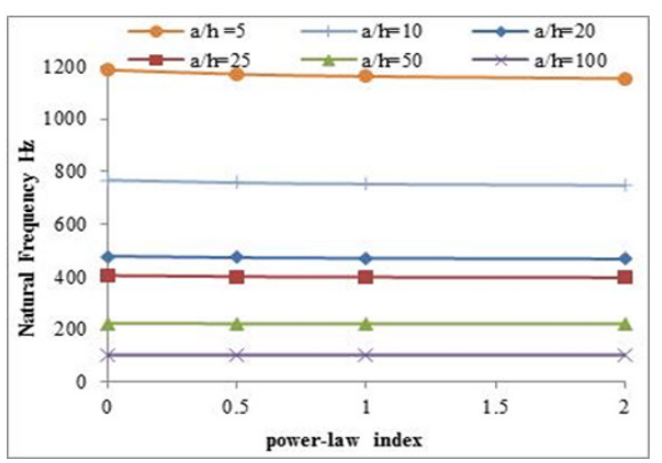

Figure 8 . Results of the frequency at Beta $=0.1$, for various slenderness ratios $(a / h)$ 


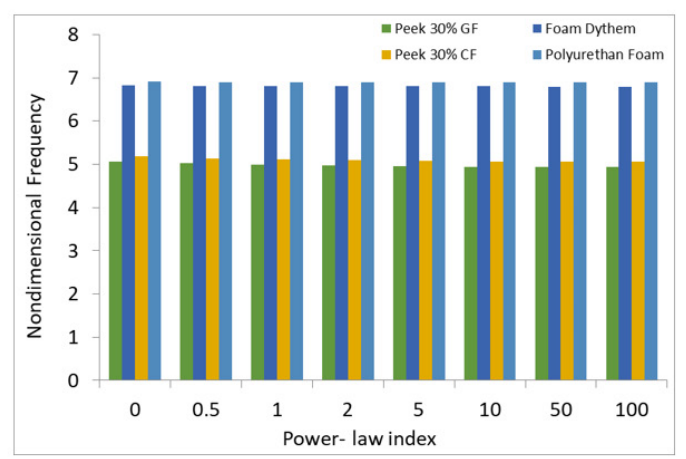

Figure 9. Results of the natural frequency at Beta $=0.1$, for various porous metals at FG core height 10 $\mathrm{mm}$, and face thickness $2.5 \mathrm{~mm}$

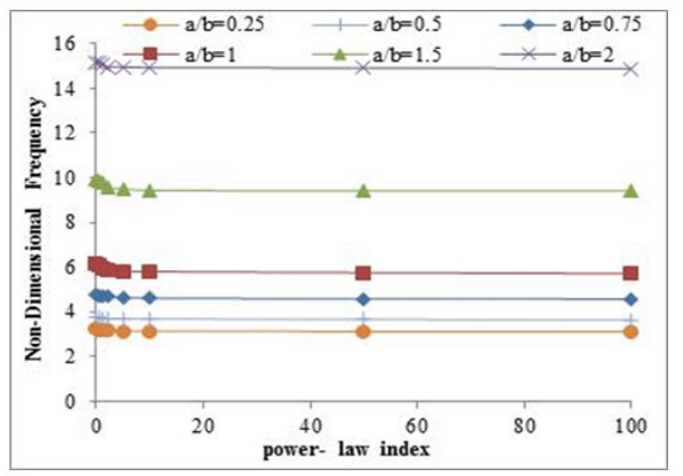

Figure 11. Frequency parameter of a rectangular plate with a different aspect ratio $(a / b)$ at Beta $=0.1$, FG core $12 \mathrm{~mm}$, and skin thickness $2 \mathrm{~mm}$

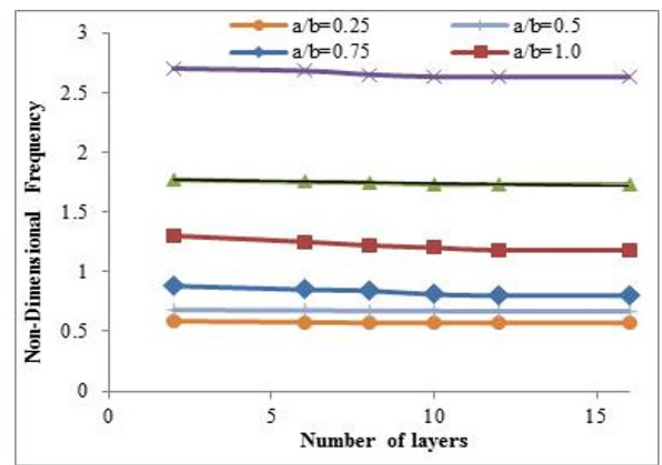

Figure 13. The natural frequency for different number of layers of FGM rectangular plate gradient index $\mathrm{k}=2$ and Beta $=0.1$

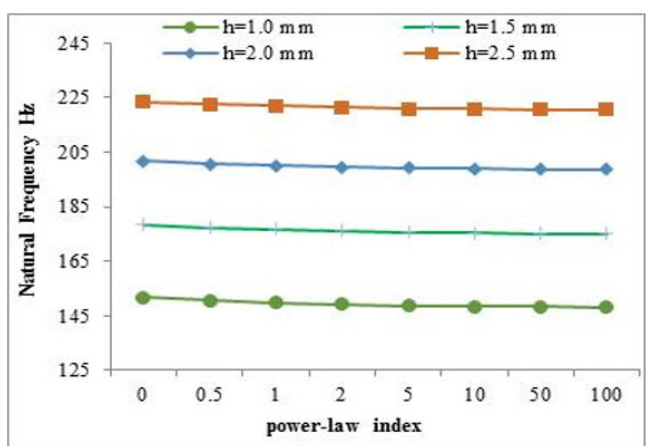

Figure 10. Results of the natural frequency at Beta $=0.1$, for various face sheet thicknesses with FGM core height $5 \mathrm{~mm}$

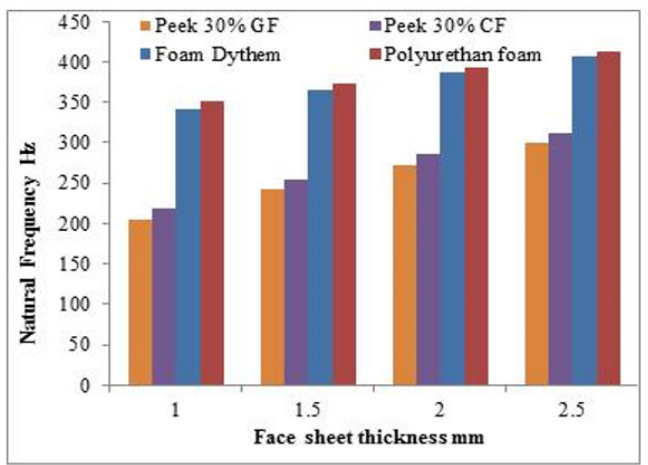

Figure 12. Results of the natural frequency at Beta $=0.1$, for various face sheet thicknesses

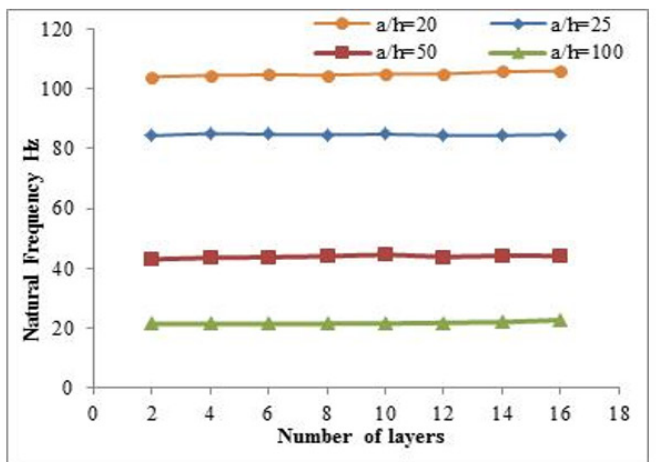

Figure 14. The natural frequency for different number of layers of FGM square plate with gradient index $\mathrm{k}=2$ and Beta $=0.1$ 


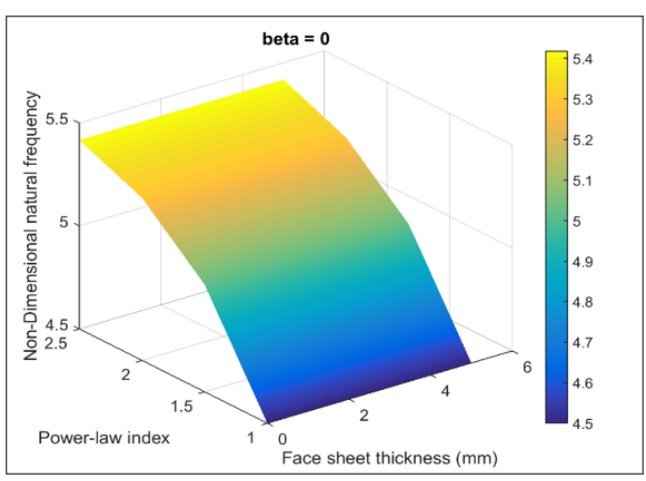

Figure 15. 3D Surface of the frequency parameter of the square sandwich plate at Beta $=0$

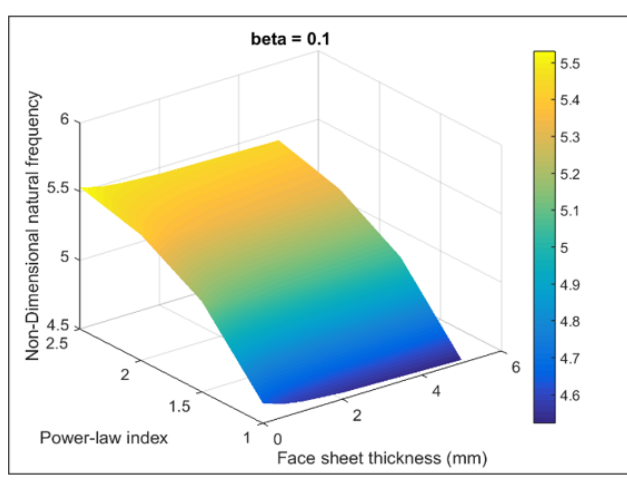

Figure 16.3D Surface of the frequency parameter of the square sandwich plate at Beta $=0.1$

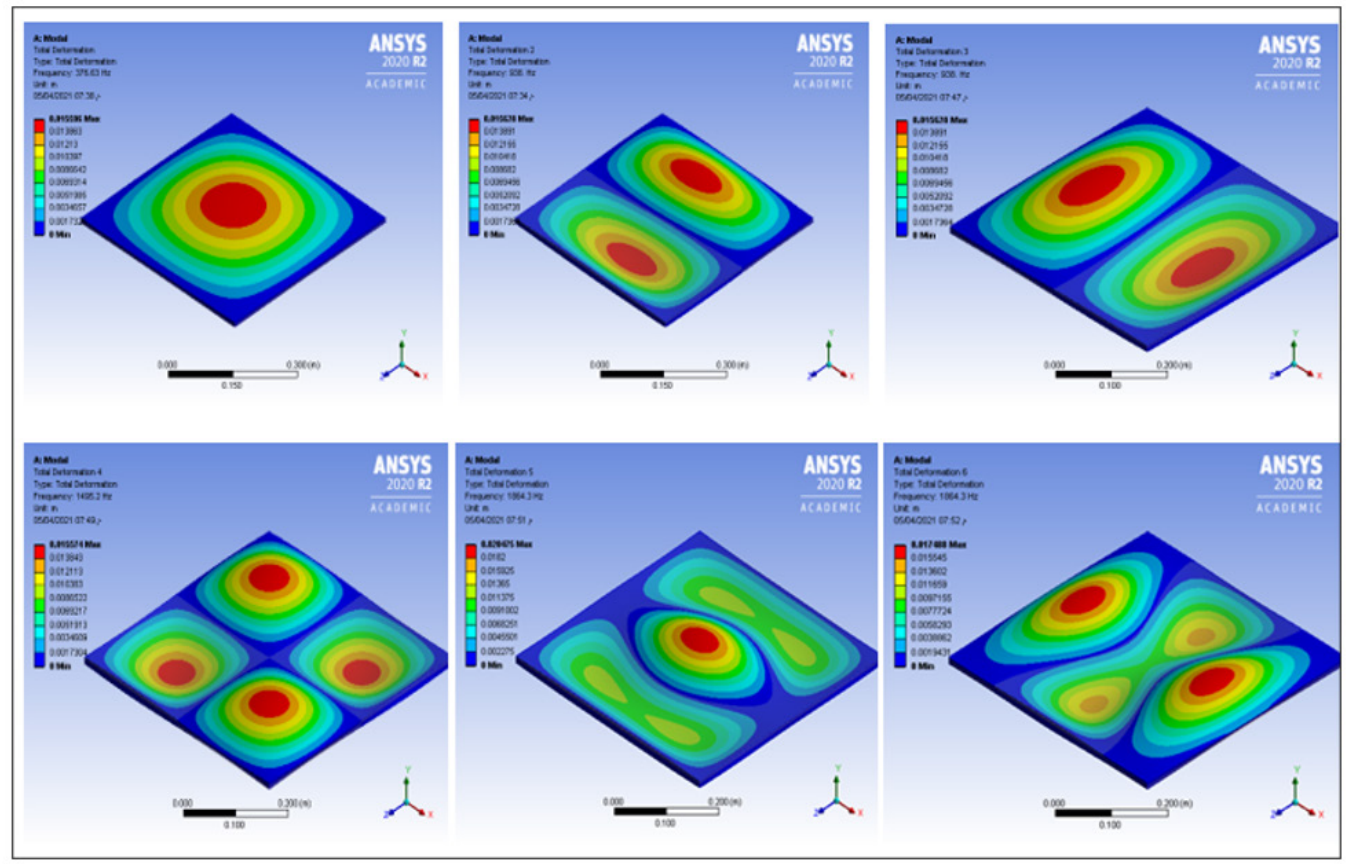

Figure 17. The first six mode shapes of simply supported FGM square sandwich plate at Beta=0.0, $k=0.5$

\section{CONCLUSION}

In this paper, free vibration of functionally graded porous sandwich plate if the material properties vary depending on the thickness with a power distribution are examined. A simple and new accurate mathematical model using CPT principles was presented. The sandwich plate comprises one phase porous metal (Polyethylene, Peek, \& Foam) core gluing with 
homogeneous skins onto two sides using suitable adhesion. The analytical formulation for free vibration analysis of simply supported plates is provided to predict the free vibration characteristics. A numerical investigation is carried out using ANSYS 2020 R2 to confirm the results of analytical modeling. Results for specific aspect ratio values, FG core material and thickness, face sheet thickness, porous factor, and type of boundary conditions are presented. The paper also explores the impact of various parameters on the free vibration characteristics of the functionally graded sandwich plates such as porous factor, gradient index, as well as aspect ratio. From the above, it can be noticed that:

- It can be observed that the natural frequencies increase with the increased porous factor and decrease with an increase in the volume fraction index $k$ because of a reduction in the volumetric percentage of the core material.

- Lower porosity parameter (Beta) indicates higher structural stiffness, consequently, higher dimensionless natural frequency.

- It can be distinctly shown from the figures and tables, that both of the aspect ratios $(a / b)$ and slenderness ratios $(a / h)$, as well as different material distributions, play vital roles to check the free vibration characteristics of FG sandwich structure.

- The assessment of the impact of porous metal type and porosity distribution characteristics on the performance of the FGM structure confirmed that the Polyathelen foam is the correct choice than other types used in this study.

- Though simplifications are considered in the analytical model, the obtained results show good agreement with FE simulations; the error percentage did not exceed $6 \%$. This percentage increase as the thickness ratio increases in both thickness ratio and gradient index; for example, the error will be diminished with increasing of the thickness ratio $(a / H=100)$ at $k=100$.

- The plate frequency parameter increases with the constraint to the boundary conditions; for example, the frequency parameter for CCCC is higher than CCCS. This condition is more than CSCS, and so on, as shown in Table 5. Also from Table 5 , it can be concluded that frequencies are increasing with an increase in porosity ratio regardless of the edge conditions and FG parameters considered.

- For the FG core consists of multilayers, it is found that the distribution of natural frequency across the thickness indicates a smooth variation of the same compared to those obtained in the case of the conventional laminated plates.

\section{ACKNOWLEDGEMENT}

The authors would like to thank the University of Technology and the University of Kufa, Iraq, to support and fund this study. 


\section{REFERENCES}

Al-Waily, M., Al-Shammari, M. A., \& Jweeg, M. J. (2020). An analytical investigation of thermal buckling behavior of composite plates reinforced by carbon nano-particles. Engineering Journal, 24(3),11-21. https://doi.org/10.4186/ej.2020.24.3.11

Ambartsumyan, S. A., Ashton, J. E. (Ed), \& Cheron, T. (Trans). (1970). Theory of Anisotropic Plates: Strength, Stability, and Vibration (Progress in Materials Science Series, Vol. 2). Technomic Publishing Company

Anderson, T. (2003). A 3-D elasticity solution for a sandwich composite with functionally graded core subjected to transverse loading by a rigid sphere. Composite Structures, 60(3), 265-274. https://doi.org/10.1016/ S0263-8223(03)00013-8

Baferani, A. H., Saidi, A. R., \& Ehteshami, H. (2011). Accurate solution for free vibration analysis of functionally graded thick rectangular plates resting on elastic foundation. Composite Structures, 93(7), 1842-1853. https://doi.org/10.1016/j.compstruct.2011.01.020

Bonnheim, N., Ansari, F., Regis, M., Bracco, P., \& Pruitt, L. (2019). Effect of carbon fiber type on monotonic and fatigue properties of orthopedic grade PEEK. Journal of the mechanical behavior of biomedical materials, 90, 484-492. https://doi.org/10.1016/j.jmbbm.2018.10.033

Burlayenko, V. N., \& Sadowski, T. (2020). Free vibrations and static analysis of functionally graded sandwich plates with three-dimensional finite elements. Meccanica, 55(4), 815-832. https://doi.org/10.1007/s11012019-01001-7

Chakraverty, S., \& Pradhan, K. K. (2014). Free vibration of exponential functionally graded rectangular plates in thermal environment with general boundary conditions. Aerospace Science and Technology, 36, 132156. https://doi.org/10.1016/j.ast.2014.04.005

Chi, S., \& Chung, Y. (2006). Mechanical behavior of functionally graded material plates under transverse load-Part I: Analysis. International Journal of Solids and Structures, 43(13), 3657-3674. https://doi. org/10.1016/j.ijsolstr.2005.04.011

Coskun, S., Kim, J., \& Toutanji, H. (2019). Bending, free vibration, and buckling analysis of functionally graded porous micro-plates using a general third-order plate theory. Journal of Composites Science, 3(1), Article 15. https://doi.org/10.3390/jcs3010015

Cui, J., Zhou, T., Ye, R., Gaidai, O., Li, Z., \& Tao, S. (2019). Three-dimensional vibration analysis of a functionally graded sandwich rectangular plate resting on an elastic foundation using a semi-analytical method. Materials, 12(20), Article 3401. https://doi.org/10.3390/ma12203401

Dang, Y. H., Li, Y. H., Chen, D., \& Yang, J. (2018). Vibration characteristics of functionally graded graphene reinforced porous nanocomposite cylindrical shells with spinning motion. Composites Part B: Engineering, 145, 1-13. https://doi.org/10.1016/j.compositesb.2018.03.009

Goel, M. D., Matsagar, V. A., Marburg, S., \& Gupta, A. K. (2013). Comparative performance of stiffened sandwich foam panels under impulsive loading. Journal of performance of constructed facilities, 27(5), 540-549. https://doi.org/10.1061/(ASCE)CF.1943-5509.0000340

Hadji, L., Atmane, H. A., Tounsi, A., Mechab, I., \& Bedia, E. A. (2011). Free vibration of functionally graded sandwich plates using four-variable refined plate theory. Applied Mathematics and Mechanics, 32, 925942. https://doi.org/10.1007/s10483-011-1470-9 
Hayat, S., \& Meriem, S. (2019). Vibration analysis of functionally graded plates with porosity composed of a mixture of Aluminium $(\mathrm{Al})$ and Alumina $\left(\mathrm{Al}_{2} \mathrm{O}_{3}\right)$ embedded in an elastic medium. Frattura ed Integrità Strutturale, 13(50), 286-299. https://doi.org/10.3221/IGF-ESIS.50.24

Kapuria, S., Bhattacharyya, M., \& Kumar, A. N. (2008). Bending and free vibration response of layered functionally graded beams: A theoretical model and its experimental validation. Composite Structures, 82(3), 390-402. https://doi.org/10.1016/j.compstruct.2007.01.019

Kiani, Y., \& Eslami, M. R. (2012). Thermal buckling and post-buckling response of imperfect temperaturedependent sandwich FGM plates resting on elastic foundation. Archive of Applied Mechanics, 82, 891-905. https://doi.org/10.1007/s00419-011-0599-8

Kiani, Y., Bagherizadeh, E., \& Eslami, M. R. (2011). Thermal and mechanical buckling of sandwich plates with FGM face sheets resting on the Pasternak elastic foundation. Proceedings of the Institution of Mechanical Engineers, Part C: Journal of Mechanical Engineering Science, 226(1), 32-41. https://doi. org/10.1177/0954406211413657

Kim, J., Żur, K. K., \& Reddy, J. N. (2019). Bending, free vibration and buckling of modified couples stress-based functionally graded porous micro-plates. Composite Structures, 209, 879-888. https://doi.org/10.1016/j. compstruct.2018.11.023

Kumar, V., Singh, S. J., Saran, V. H., \& Harsha, S. P. (2021). Vibration characteristics of porous FGM plate with variable thickness resting on Pasternak's foundation. European Journal of Mechanics-A/Solids, 85, Article 104124. https://doi.org/10.1016/j.euromechsol.2020.104124

Lashkari, M. J., \& Rahmani, O. (2016). Bending behavior of sandwich structures with flexible functionally graded core based on high-order sandwich panel theory. Meccanica, 51(5), 1093-1112. https://doi. org/10.1007/s11012-015-0263-4

Latif, M., Farhatnia, F., \& Kadkhodaei, M. (2013). Buckling analysis of rectangular functionally graded plates under various edge conditions using Fourier series expansion. European Journal of Mechanics - A/Solids, 41, 16-27. https://doi.org/10.1016/j.euromechsol.2013.01.008

Leissa, A. W. (1969). Vibration of plates (Vol. 160). Scientific and Technical Information Division, National Aeronautics and Space Administration.

Liu, Y., Hu, Y., Liu, T., Ding, J. L., \& Zhong, W. H. (2015). Mechanical behavior of high density polyethylene and its carbon nanocomposites under quasi-static and dynamic compressive and tensile loadings. Polymer Testing, 41, 106-116. https://doi.org/10.1016/j.polymertesting.2014.11.003

Meiche, N. E., Tounsi, A., Ziane, N., Mechab, I., \& Bedia, E. A. (2011). A new hyperbolic shear deformation theory for buckling and vibration of functionally graded sandwich plate. International Journal of Mechanical Sciences, 53(10), 237-247. https://doi.org/10.1016/j.ijmecsci.2011.01.004

Merdaci, S. (2019). Free vibration analysis of composite material plates case of a typical functionally graded FG plates ceramic/metal with porosities. Nano Hybrids and Composites, 25, 69-83. https://doi.org/10.4028/ www.scientific.net/NHC.25.69

Meziane, M. A. A., Abdelaziz, H. H., \& Tounsi, A. (2014). An efficient and simple refined theory for buckling and free vibration of exponentially graded sandwich plates under various boundary conditions. Journal of Sandwich Structures and Materials, 16(3), 293-318. https://doi.org/10.1177/1099636214526852 
Muc, A., \& Flis, J. (2021). Flutter characteristics and free vibrations of rectangular functionally graded porous plates. Composite Structures, 261, 113301. https://doi.org/10.1016/j.compstruct.2020.113301

Najim, A. S., \& Adwaa, M. (2014). Studying mechanical properties specially fatigue behavior of (polyether ether ketone)/glass fiber composites in aerospace applications. In Applied Mechanics and Materials (Vol. 666, pp. 8-16). Trans Tech Publications Ltd. https://doi.org/10.4028/www.scientific.net/AMM.666.8

Natarajan, S., \& Manickam, G. (2012). Bending and vibration of functionally graded material sandwich plates using an accurate theory. Finite Elements in Analysis and Design, 57, 32-42. https://doi.org/10.1016/j. finel.2012.03.006

Neves, A. M. A., Ferreira, A. J. M., Carrera, E., Cinefra, M., Roque, C.M.C., Jorge, R. M. N., \& Soares, C. M. M. (2013). Static, free vibration and buckling analysis of isotropic and sandwich functionally graded plates using a quasi-3D higher-order shear deformation theory and a meshless technique. Composites Part B: Engineering, 44(1), 657-674. https://doi.org/10.1016/j.compositesb.2012.01.089

Nguyen, N. V., Nguyen, H. X., Lee, S., \& Xuan, H. N. (2018). Geometrically nonlinear polygonal finite element analysis of functionally graded porous plates. Advances in Engineering Software, 126, 110-126. https:// doi.org/10.1016/j.advengsoft.2018.11.005

Rao, S. S. (2004). The finite element method in engineering. Elsevier.

Reddy, J. N. (1993). An introduction to the finite element method. McGraw-Hill, Inc.

Rezaei, A. S., \& Said, A. R. (2015). Exact solution for free vibration of thick rectangular plates made of porous materials. Composite Structures, 134, 1051-1060. https://doi.org/10.1016/j.compstruct.2015.08.125

Sadiq, S. E., Jweeg, M. J., \& Bakhy, S. H. (2020). The effects of honeycomb parameters on transient response of an aircraft sandwich panel structure. In IOP Conference Series: Materials Science and Engineering (Vol. 928, No. 2, p. 022126). IOP Publishing.

Singh, S. A., \& Harsha, S. P. (2020). Thermo-mechanical analysis of porous sandwich S-FGM plate for different boundary conditions using Galerkin Vlasov's method: A semi-analytical approach. Thin-Walled Structures, 150, Article 106668. https://doi.org/10.1016/j.tws.2020.106668

Thai, H. T., Nguyen, T. K., Vo, T. P., \& Lee, J. (2013). Analysis of functionally graded sandwich plates using a new first-order shear deformation theory. European Journal of Mechanics-A/Solids, 45, 211-225. https:// doi.org/10.1016/j.euromechsol.2013.12.008

Tossapanon, P., \& Wattanasakulpong, N. (2020). Flexural vibration analysis of functionally graded sandwich plates resting on elastic foundation with arbitrary boundary conditions: Chebyshev collocation technique. Journal of Sandwich Structures and Materials, 22(2), 156-189. https://doi.org/10.1177/1099636217736003

Wadee, M. A. (2001). Shear Deformable Beams and Plates: Relationships with Classical Solutions-CM Wang, JN Reddy and KH Lee, Elsevier, 2000, pp. 312,@ \$69.30, ISBN 0080437842. Engineering Structures, $7(23), 873-874$.

Wang, Y. Q., \& Zu, J. W. (2017). Vibration behaviors of functionally graded rectangular plates with porosities and moving in thermal environment. Aerospace Science and Technology, (69), 550-562. https://doi. org/10.1016/j.ast.2017.07.023 
Wattanasakulpong, N., \& Chaikittiratana, A. (2015). Flexural vibration of imperfect functionally graded beams based on Timoshenko beam theory: Chebyshev collocation method. Meccanica, 50(5), 1331-1342. https:// doi.org/10.1007/s11012-014-0094-8

Wattanasakulponga, N., \& Ungbhakorn, V. (2014). Linear and nonlinear vibration analysis of elastically restrained ends FGM beams with porosities. Aerospace Science and Technology, 32(1), 111-120. https:// doi.org/10.1016/j.ast.2013.12.002

Zhang, X. Y., Fang, G., Leeflang, S., Zadpoor, A. A., \& Zhou, J. (2019). Topological design, permeability and mechanical behavior of additively manufactured functionally graded porous metallic biomaterials. Acta Biomaterialia, 84, 437-452. https://doi.org/10.1016/j.actbio.2018.12.013

Zhang, Y., \& Wang, J. (2017). Fabrication of functionally graded porous polymer structures using thermal bonding lamination techniques. Procedia Manufacturing, 10, 866-875. https://doi.org/10.1016/j. promfg.2017.07.073

Zhao, J., Wang, Q., Deng, X., Choe, K., Zhong, R., \& Shuai, C. (2019). Free vibrations of functionally graded porous rectangular plate with uniform elastic boundary conditions. Composites Part B: Engineering, 168, 106-120. https://doi.org/10.1016/j.compositesb.2018.12.044 